\title{
Carme Oriol y Emili Samper (eds.), Història de la literatura popular catalana, Alicante / Palma/ Tarragona, Universitat Rovira i Virgili / Universitat d'Alacant / Universitat de les Illes Balears, 2017, $601 \mathrm{pp}$.
}

En el Romanticismo, con el surgimiento de la Renaixença, se desató un gran interés por la literatura oral en catalán, que ha seducido a muchos folcloristas, filólogos, escritores y antropólogos desde el siglo XIX hasta nuestros días, y que ha dado como fruto grandes obras y proyectos de documentación y estudio del folclore en las regiones catalana, valenciana y balear, así como en otros enclaves catalanoparlantes.

Afortunadamente, hoy más que nunca, se estudia con rigor la literatura tradicional catalana, una literatura que, tanto por su carácter popular como por la discriminación que sufrió esta lengua durante la dictadura franquista, fue denostada por intelectuales y políticos durante un largo periodo de tiempo. Un buen ejemplo de rigor metodológico lo encontramos en esta Història de la literatura popular catalana, un trabajo sin precedentes -nunca antes, en el ámbito lingüístico catalán, se había escrito un estudio tan amplio desde el punto de vista territorial y cronológico-, que documenta con especial lujo de detalles los estudios de literatura popular en catalán desde el siglo XIX hasta nuestros días.

No cabe duda de que este tipo de obras son muy necesarias también en el ámbito de la literatura oral hispánica. A este respecto ya se pronunciaba Pedro C. Cerrillo (2011: 9), donde apuntaba que las historias de la literatura, salvo honradas excepciones, prestaban poca atención a la literatura de tradición oral. Como respuesta a la escasez de obras que dibujaran un estado de la cuestión de los estudios de literatura oral en el territorio español y en la tradición sefardí, surgió el primer número extraordinario del Boletín de Literatura Oral (2017). En este número participó una importante nómina de especialistas, entre los que se encuentran las coautoras de este volumen, Carme Oriol -que trazó un estudio sobre los fondos documentales actuales sobre narrativa oral en Cataluña-, y Caterina Valriu — que realizó una aproximación histórica al folclore de las Islas Baleares-.

Esta Història de la literatura popular catalana, coordinada por los filólogos Carme Oriol y Emili Samper, también es una obra colectiva, que ha sido gestada por 16 investigadores pertenecientes a diferentes universidades, centros de investigación y centros de educación secundaria, como son Martine Berthelot, Joan Borja, August Bover, Jaume Guiscafrè, Hèctor Moret, Montserrat Palau, Isabel de la Parte, Artur Quintana, Josefina Roma, Mònica Sales, Josep Temporal, Caterina Valriu, Vicent Vidal y Laura Villalba, y los ya citados Oriol y Samper. La mayor parte de ellos han colaborado en proyectos como el Repertori Bibliogràfic de la Literatura Popular Catalana, cuyos resultados han sido recogidos en la base de datos Bibliofolk (Oriol, 2006-2015), que contiene las referencias bibliográficas de las obras sobre literatura oral y popular catalana escritas desde 1778 hasta 2015. En el marco de este proyecto también se publicó el catálogo colectivo Repertori biobibliogràfic de la literatura popular catalana: el cicle romàntic (2011), editado por Carme Oriol y Emili Samper. Asimismo, algunos de estos 
investigadores han publicado estudios de alcance más reducido, como la «Introduction» al Index of Catalan Folktales (2008), escrita por Carme Oriol y Josep M. Pujol, que recoge las aportaciones de los principales folcloristas a la cuentística catalana. Por otra parte, Carme Oriol es la directora de la publicación Estudis de Literatura Oral Popular, una de las escasas revistas españolas consagradas a la materia, que nació en 2012 y que en la actualidad cuenta con 7 números.

Heredera del trabajo previo de sus autores, la obra aquí reseñada tiene como objetivo principal ofrecer un estado de la cuestión amplio y general de la literatura popular en el ámbito lingüístico y cultural catalán. Una de sus principales virtudes es su carácter multidisciplinar, ya que engloba géneros muy diversos - en ocasiones, un tanto alejados de la literatura pero estrechamente ligados con el folclore y la tradición, como los bailes y las fiestas- Asimismo, muestra una gran nómina de obras, investigadores y folcloristas (algunos de ellos poco conocidos), que han hecho posible que los estudios de literatura popular catalana gocen de una salud envidiable.

El libro se estructura en siete capítulos, cada uno de los cuales se centra en el estudio de una zona catalanoparlante. De esta forma, los cuatro primeros capítulos están consagrados a las regiones y zonas que pertenecen al estado español: Cataluña, Islas Baleares, Valencia y el Carxe (Murcia) y la Franja de Aragón; mientras que los tres últimos están dedicados a Andorra, Cataluña del Norte - que comprende las comarcas francesas de Rosellón, Vallespir, Conflent, Cerdaña y Capcir-, y la ciudad de Alguer, en la isla de Cerdeña. Destaca en especial el capítulo dedicado a Cataluña, un profuso estudio de 200 páginas, en el que se repasan las contribuciones de grandes folcloristas del siglo XIX y XX, como Milá y Fontanals o Joan Amades; se relata la aproximación a la documentación y estudio de la literatura popular por parte de las mujeres durante el primer tercio del siglo XX; se describen los principales proyectos de la archivística folclórica desde finales del XIX y se da cuenta de la situación actual de los estudios sobre literatura oral, la mayoría de ellos financiados desde el ámbito institucional y universitario, y realizados por parte de antropólogos, musicólogos, filólogos y pedagogos.

De igual manera, destacan los extensos capítulos dedicados a las Islas Baleares y al País Valenciano y el Carxe. El resto de capítulos son más breves, aunque es un hecho totalmente justificable si se tiene en cuenta que la historia de la literatura oral en cada una de las zonas catalanoparlantes tiene su propia idiosincrasia. Como ejemplo podemos señalar el caso particular de Andorra, donde se llevaron a cabo trabajos muy dispersos hasta mediados del siglo XIX, cuando las instituciones locales se comenzaron a interesar por el rescate del folclore.

No obstante la distinta autoría y desigual extensión de los capítulos, el libro cuenta con un hilo conductor que le otorga cohesión estructural: en cada capítulo se hace referencia a las interrelaciones e influencias entre los estudios e investigaciones llevados a cabo en los distintos territorios catalanoparlantes.

En definitiva, esta Història de la literatura popular catalana ofrece al investigador una nutrida lista de referencias bibliográficas y le permite apreciar la evolución general de los estudios dedicados a la literatura oral desde mediados del siglo XIX hasta nuestros días. Este volumen se constituye, por tanto, como un estudio novedoso, que recuerda la labor de los grandes folcloristas e investigadores de la tradición oral en catalán, a la vez que reivindica la figura de aquellos que, sin haber obtenido tanto reconocimiento, contribuyeron con su trabajo a documentar y dignificar una literatura no siempre apreciada. 


\section{BIBLIOGRAFÍA}

CERrillo, Pedro C. (2010): «Memoria, oralidade e escritura. Sobre literatura oral e literatura escrita», Boletín Galego de Literatura, 44, pp. 7-29.

URL: <http://hdl.handle.net/10347/7558>

MAÑERo LOZANO, David y GONZÁLEZ RAMÍREZ, David (coords.) (2017): Los paisajes de la voz. Literatura oral e investigaciones de campo, Boletín de Literatura Oral, Número Extraordinario I, Jaén, Universidad de Jaén.

DOI: https://doi.org/10.17561/blo.vextrai1

Miriam Pimentel García

(Universidad de Jaén)

$$
9
$$

